\title{
An initial study of biogas upgrading to bio- methane with carbon dioxide capture using ceramic membranes.
}

OGUNLUDE, P., ABUNUMAH, O., ORAKWE, I., SHEHU, H., MUHAMMAD-SUKKI, F. and GOBINA, E. 


\section{An Initial Study of Biogas Upgrading to Bio-Methane with Carbon dioxide Capture using Ceramic Membranes}

Priscilla Ogunlude, Ofasa Abunumah, Ifeyinwa Orakwe, Habiba Shehu, Firdaus MuhammadSukki and Edward Gobina* Centre for Process Integration and Membrane Technology School of Engineering Robert Gordon University

Garthdee Road

Aberdeen

AB10 7GJ

*Corresponding Author's mail: e.gobina@rgu.ac.uk, +441224262309

\section{ABSTRACT}

Supplement to the depleting energy resources and the stringent environmental laws regarding the atmospheric emissions of greenhouse gases, the development of clean and renewable sources of energy has been a great issue. Worldwide, energy usage is steadily increasing and would continue to increase in the coming years; the effects of global warming are also becoming more and more prevalent. Biogas holds a promising future in the sustainable supply of low-cost energy that will minimize greenhouse gas emissions. Unlike solar and wind, biogas does not rely on weather conditions. It can also be stored and transported making it easily adaptable to changes in demand. This study would utilize membrane technology for the upgrading of biogas to a clean and useful fuel replacing fossil fuels and consider the limiting factors of the process found in literature which is the tradeoff between gas permeability and selectivity. In doing so, we analyse the factors that affect permeability and selectivity of ceramic membranes and then introduce methods of optimisation. Biogas components are passed through the membrane as feed gas to observe the flow characteristics at various operating conditions for membranes with different pore sizes. It was observed that for all pore sizes studied, there was a proportional rise in flowrate as the feed pressure was increased from 0.2 to 3 bar. Also, an increase in temperature from $20^{\circ} \mathrm{C}$ to $100^{\circ} \mathrm{C}$ favoured the membrane selectivity. In general, methane gas showed a higher flux than carbon dioxide irrespective of the operating conditions indicating that the permeation of the gases is related to their molecular weight, for example, using $15 \mathrm{~nm}$ membrane at $20^{\circ} \mathrm{C}$ and $3 \mathrm{bar}$, a flux of 3.59 and $2.27 \mathrm{l} / \mathrm{min}$ was obtained for $\mathrm{CH}_{4}$ and $\mathrm{CO}_{2}$ respectively with the same trend recorded using other pore sizes, temperature and pressure ranges. It must also be noted that the pore size plays a vital role in the optimisation of membrane process as the $15 \mathrm{~nm}$ membrane, being the lowest mean pore size studied showed the highest separation factor of 1.60 which is close to the ideal Knudsen value. Overall, it was found that the behaviour of gases through these membranes is determined by an interplay of factors - dynamic size and diffusion rate.

Keywords: Biogas, upgrading, sustainable, membrane, carbon dioxide capture, biomethane 


\section{INTRODUCTION}

The emission of greenhouse gases (GHGs) have been found as a major contributing factor to global warming. These emissions are usually fostered by manmade activities such as burning of fossil fuels to provide energy, dumping at landfill sites which does not only pollute the environment but wastes vital resources including land, deforestation and many more. When greenhouse gases are released into the atmosphere, heat is trapped (that is, the heat is not allowed to dissipate into space) thereby causing an imbalance of what amount of energy that comes from the sun to the earth and back (1). This has a massive impact on the earth surface which leads to temperature changes, drying/drought and other transformations in the ecosystem. Evidence has shown that there is a direct link between global warming and climate change, this has made the need for capturing greenhouse gases a matter of global urgency in recent decades (2).

Global warming is described as an increase in the overall air temperature near the earth's surface. In recent times, there have been unfortunate documented events of disasters directly linked to climate change. For instance, Europe experienced a terrible heat wave with Paris reaching its highest ever recorded temperature of $42.5^{\circ} \mathrm{C}$; parts of the United States of America suffered flooding; the people of Chennai in India faced droughts; Australia faced terrible wild fires; and Britain's crop shortage due to drought posed a problem in the food sector. All these events and more have raised an awareness to the effects of global warming and government bodies have also begun to strategize on how to combat this issue of climate change which has led to the introduction of environmental regulations to encourage the use of renewable forms of energy. Some of these include carbon costing, the UK net-zero emissions by 2050, and a cap on the fraction of renewable fuels that are crop based.

\section{THEORY}

Biogas is produced by the anaerobic digestion of waste materials derived from sewage, landfill, food waste and organic matter. It consists primarily of methane and carbon dioxidethese gases would normally rise and contribute to the greenhouse gases present in the atmosphere or alternatively, the gases can be collected and repurposed as a beneficial resource to be harnessed as a source of energy(3). Compared to other forms of renewable energy such as solar and wind energy which depend on environmental factors for use, biogas is advantageous as it is readily available from waste which is deposited on a daily basis.

Currently, upgrading biogas to the required specification for injection into the national gas grid requires the use of absorption, adsorption, membrane or cryogenic methods (4). This paper would focus on the use of membrane technology for upgrading biogas. The two major types of membranes include polymer and inorganic membranes. Polymer membranes can be subdivided into porous and non-porous membranes and their use in industrial processes depend on the properties of the membrane and the intended application. Even though polymer membranes have been studied over time for use in gas separation, their constraints of low chemical and thermal stability have limited their usage in industrial application. Recently, inorganic membranes have been gaining interest as they supersede 
polymer membranes in terms of chemical and thermal stability. Some types of inorganic membranes include ceramic membranes formed by combining a metal and non-metal oxide, nitride or carbide; glass membranes which are made by leaching on de-mixed glasses; and metallic membranes obtained by sintering of metal powders. These membranes may be porous or non-porous. Porous membranes contain fixed pores and their selectivity is dependent on the pore size but their physical and chemical properties which interpret the permeability depend on the material used and method of preparation. On the other hand, the non-porous membrane depends on the intrinsic properties of the material. Porous membranes are characterized by pore size, porosity and tortuosity. Generally, pore sizes range from microporous ( $d p<2 n m)$, mesoporous $(2 n m<d p<50 n m)$ and macroporous $(d p>50 n m)(5)$. For this study, ceramic membranes are chosen due to their versatility (for use in separation and reaction processes), high stability, long life-span, compact size, low energy demand, high efficiency and high resistance to aggressive chemical environment or harsh environmental conditions of temperature and pressure which prevail in industry.

\section{MATERIALS AND METHODS}

The membranes used were characterised by scanning electron microscopy (SEM) and composed of alumina material (77\%) with a wash coat of titania (23\%). Each membrane was inserted into a tubular metallic casing covered in heating tape with inlet and outlet lines in the tube and shell sides. The inlet was connected to the gas cylinder containing sample gas and leak tests were conducted by pressurizing the system at double the pressure intended for the experiments and noting if there were any pressure drops along the line, a snoop solution was also used at connection points. Pure gas samples of $\mathrm{CH}_{4}$ and $\mathrm{CO}_{2}$ supplied by BOC Gases, UK were passed through the membranes at pressures ranging from 0.2 to 3 bar and temperatures 25 to $100^{\circ} \mathrm{C}$. Flow measurements were taken from the outlet sides and analysed.

Table 1 Characteristics of the membranes

\begin{tabular}{|l|l|l|l|l|l|}
\hline Membrane & $\begin{array}{l}\text { Full length } \\
(\mathrm{m})\end{array}$ & $\begin{array}{l}\text { Permeable } \\
\text { length }(\mathrm{m})\end{array}$ & $\begin{array}{l}\text { Outer } \\
\text { Diameter(m) }\end{array}$ & $\begin{array}{l}\text { Inner } \\
\text { Diameter }(\mathrm{m})\end{array}$ & Weight (g) \\
\hline $\begin{array}{l}15 \mathrm{~nm}(3 \mathrm{~mm} \\
\text { thick) }\end{array}$ & 0.365 & 0.338 & 0.01003 & 0.007046 & 49.3 \\
\hline $\begin{array}{l}15 \mathrm{~nm}(3 \mathrm{~mm} \\
\text { thick) }\end{array}$ & 0.651 & 0.602 & 0.02506 & 0.02006 & 494.7 \\
\hline $6000 \mathrm{~nm}$ & 0.368 & 0.320 & 0.02507 & 0.02007 & 272.6 \\
\hline
\end{tabular}




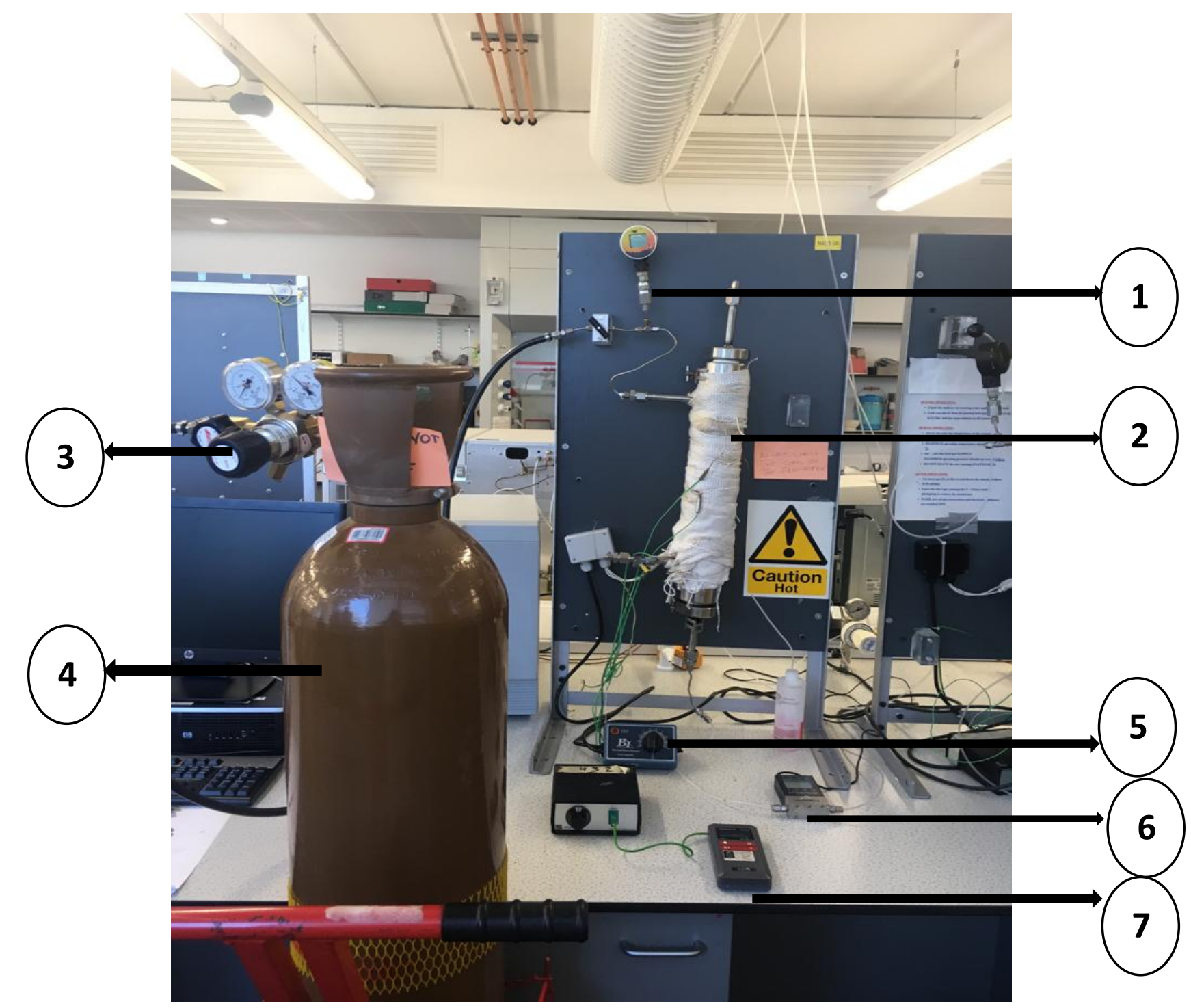

Figure 1 Experimental set-up showing all equipment including pressure gauge (1), membrane module covered with heating tape (2), gas regulator (3), gas cylinder (4), heat regulator (5), volumetric meter (6) and temperature indicator (7)

\section{RESULTS AND DISCUSSION}

Figure 2 shows the SEM images for the 15 and 6000nm membranes conducted using a Zeiss Evo LS10 S with an Oxford Instruments INCA System Energy Dispersive X-ray Analyser. The analysis was done in the order magnitude of 2000X, the difference in surface morphology is very clear with larger defects shown for membrane (b) having a greater mean pore size compared with the more closely-knit structures for membrane (a). 

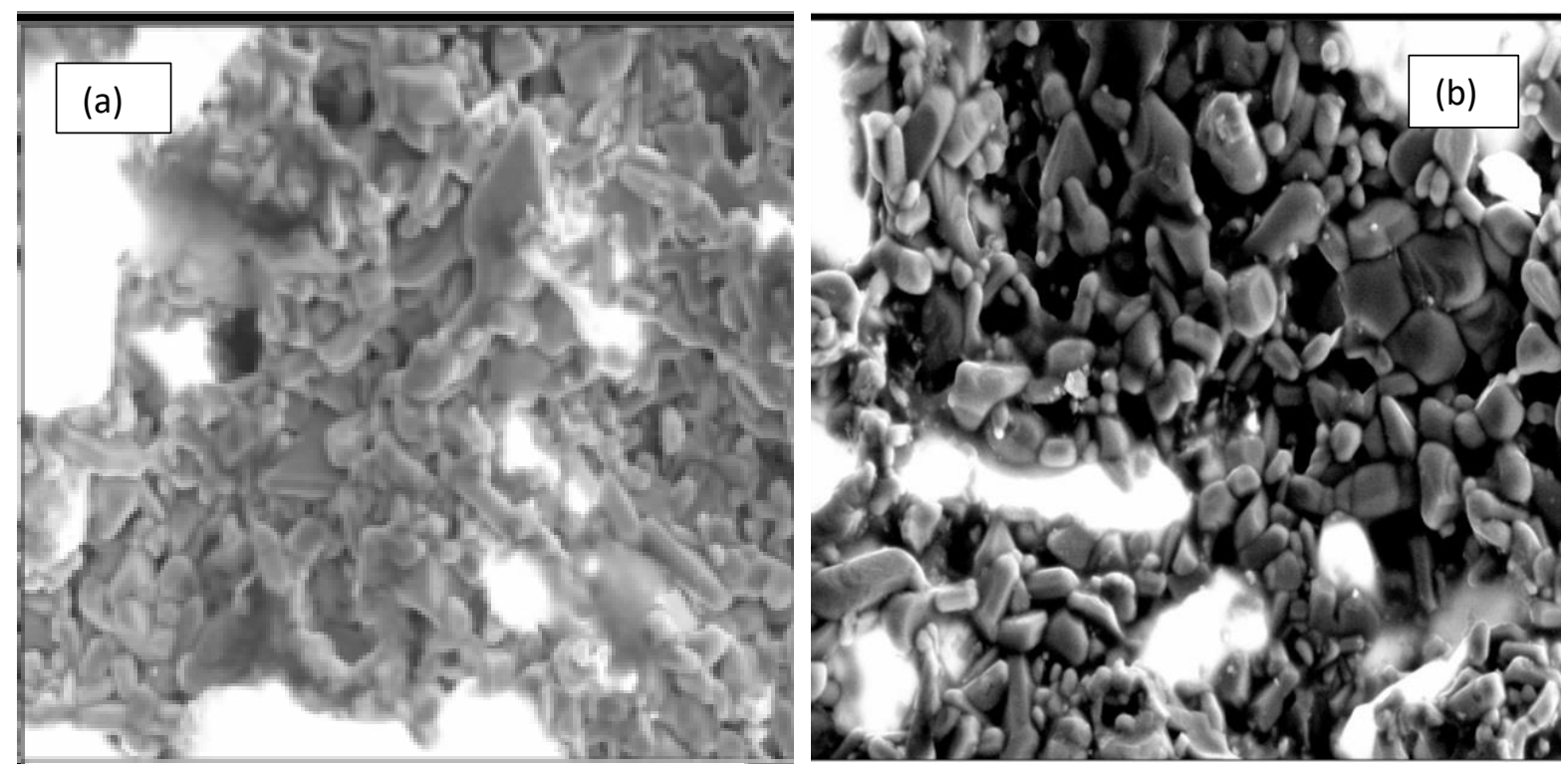

Figure 2 Outer surface SEM micrograph of (a) 15nm membrane (b) 6000nm membrane

\subsection{Effect of Pressure}

Pressure ranges between 0.2 and 3.0 bar were studied with 0.4 bar increments. Figure 4 shows the behaviour of gases as a result of pressure drop across the membrane which proves that pressure is a major driving force in determining the rate of flow for gases through the membrane as there was an exponential increase in the flowrate of both gases regardless of the membrane geometry and operating conditions (6). Methane, $\mathrm{CH}_{4}$ which has a smaller molecular weight travels through the membrane at a much faster rate than $\mathrm{CO}_{2}$ in each case. This is indicative of Knudsen regime where flow is inversely proportional to the square root of molecular mass; thus, the light gases permeate faster than the heavier ones. Nevertheless, the linear relationship between flux and pressure also suggests the influence of laminar flow (7). A key finding from this set of experiments is that the mechanism of flow through the membrane is influenced by the molecular weight of the gases for which carbon dioxide is 44 and methane is 16 .




Figure 3 Isothermal effect of Pressure on Methane Flowrate through the $15 \mathrm{~nm}$ membrane

\subsection{Effect of Temperature}

Likewise, the results demonstrate an overall increase in gas flowrate as temperature increases from $20^{\circ} \mathrm{C}$ to $100^{\circ} \mathrm{C}$. Figure 5 shows the relationship between selectivity and temperature change using one membrane under the same operating conditions. It reveals that an increase in temperature to $100^{\circ} \mathrm{C}$ considerably improves the membrane selectivity taking it above the 1.55 peak experienced at $20^{\circ} \mathrm{C}$. This can be explained by ratio of methane to carbon dioxide increasing with the rise in temperature showing that the rate of flux begins to change, improving selectivity and taking it closer to the ideal Knudsen selectivity value of 1.66 .

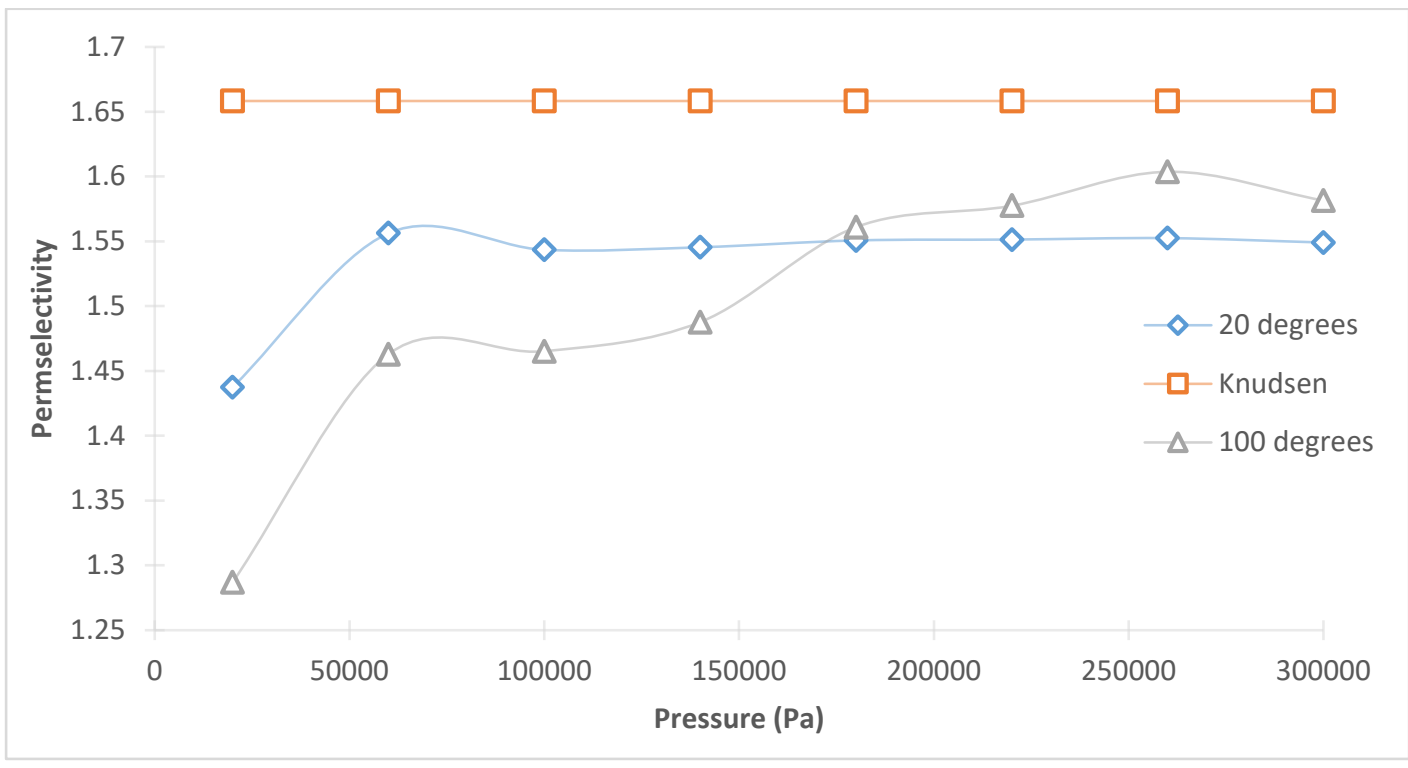

Figure 4 Selectivity performance of the $15 \mathrm{~nm}$ membrane at $20^{\circ} \mathrm{C}$ and $100^{\circ} \mathrm{C}$

\subsection{Effect of Pore Size}

Membranes with different pore sizes were evaluated to analyse how gas flow is altered within each membrane. Gas flowrates were observed to increase as the pore size increased at each pressure drop. For instance, through the $15 \mathrm{~nm}$ and $6000 \mathrm{~nm}$ membranes and under the same operating conditions of temperature and pressure, it was observed the flowrate of each gas was greater through the $6000 \mathrm{~nm}$ membrane than through the $15 \mathrm{~nm}$ membrane. This observation could be attributed to the very large pore sizes of the $6000 \mathrm{~nm}$ membrane which is categorized in the macro-porous range (8). The membrane selectivity was found to decrease with increasing pore size as the $6000 \mathrm{~nm}$ membrane shows a typically lower selectivity compared to the $15 \mathrm{~nm}$ membrane due to the very large pores that allow a nonselective viscous flow of carbon dioxide and methane through the $6000 \mathrm{~nm}$ membrane. On the other hand, the $15 \mathrm{~nm}$ membrane is characterised by Knudsen flow as discussed earlier with reduced influence of laminar flow because of the smaller pores by which it is characterised. The results show that the degree of selectivity of the membrane increased as the membrane pore size decreased as a selectivity of 1.60 (closer to the ideal knudsen 
value) was obtained for the $15 \mathrm{~nm}$ membrane whereas a maximum of 1.55 was obtained for the $6000 \mathrm{~nm}$ membrane under the same operating conditions. The difference in selectivity value for $6000 \mathrm{~nm}$ membrane means that larger amounts of big pores are present, and the effect of laminar flow is more prevalent because the mean pore size is much larger than the mean free path of the gas molecules. Hence, the results indicate that a reduction in pore size reduces the effect of laminar flow as seen in the $15 \mathrm{~nm}$ membrane (9).

\subsection{Effect of Membrane Thickness and Surface Area}

Membranes with mean pore sizes of $15 \mathrm{~nm}$ but thicknesses of $3 \mathrm{~mm}$ and $5 \mathrm{~mm}$ respectively were assessed to determine whether the thickness and surface area of the membrane plays a role in the manner in which gas is transported within the membrane. Figure 6 shows that both membranes followed a gradual rise in selectivity but the selectivity at 0.2 bar for each membrane was significantly different with the thicker membrane selectivity rising with increasing pressure and reaching the expected selectivity range around 1.8 bar. This means that the driving force for flow, i.e. pressure, had to be increased considerably in order to force the flow of gases through the pores of the thicker membrane. The results also reveal that the membrane with a larger surface area achieved higher selectivity compared with the other of smaller surface area. The improved selectivity could be an effect of more acting site that maximized contact between the gases and the surface of the ceramic membrane.

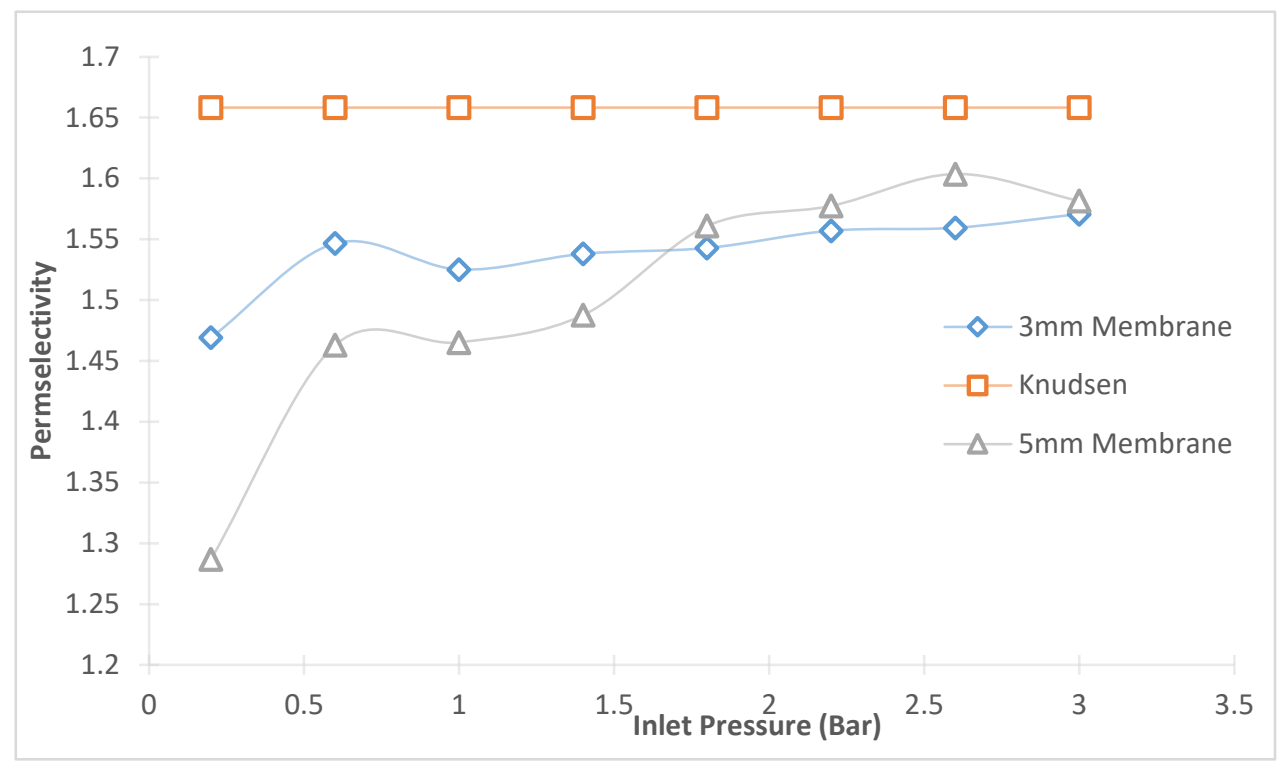

Figure 5 Comparison of selectivity performance of $15 \mathrm{~nm}$ membrane with different area

\section{CONCLUSION}

This study confirms that the membrane properties and operating conditions play a vital role in determining the flow characteristics of methane and carbon dioxide. The results show that the flux of methane is much greater than that of carbon dioxide and this large difference in flux illustrates that membrane technology is suitable for upgrading of biogas (which is a mixture consisting of carbon dioxide and methane) as each gas would flow through the membrane distinctly. In all cases studied, the gas flow mechanism is influenced 
by the gas molecular weight as the lighter methane gas moves through the membrane at a much faster rate than the heavier carbon dioxide gas which is in line with the Graham's Law of Diffusion that states the rate of flow of gases is inversely proportional to the square root of its molecular weight. According to literature, the dynamic size is a major factor that influences the rate of permeability of gases (10). However, from our experimental data, molecular weight is found to also be an important factor and thus it could be inferred that the mechanism of flow through the membranes is influenced by an interplay of factors dynamic size and diffusion rate. This is a preliminary study to show the behaviour of gases through the membrane and ascertain the optimal operating conditions that will be applied in the separation of a mixture of these gases. The results demonstrate that there is a proportional relationship between selectivity and pressure/temperature/area but an inverse relationship is observed with pore size/thickness. Having established this pattern of gas behaviour, the reconfiguration of wide-pore ceramic membranes through a repeated dipcoating and infiltration technique will be employed and reported in part II of this paper. The technique would be to modify the membranes with an agent that serves as an adsorptive medium for maximizing contact between the pore walls and the gas molecules in order to create an adsorptive layer that preferentially "draws" the target gas to its surface. It is intended to achieve a finely modified membrane with reduced pore size that can enhance the mass transport of the target gas through molecular sieving thereby increasing the overall process efficiency. By combining the method of adsorption and surface flow, it is expected that there would be an increase in the yield of the target gas without a need to desorb the adsorbent material in a cyclical fashion which reduces significantly the amount of energy used for the upgrading process.

\section{REFERENCES}

1. Akorede MF, Hizam H, Ab Kadir MZA, Aris I, Buba SD. Mitigating the anthropogenic global warming in the electric power industry. Renewable and Sustainable Energy Reviews. 2012 Jun 1;16(5):2747-61.

2. Lashof DA, Ahuja DR. Relative contributions of greenhouse gas emissions to global warming. Nature. 1990;344(6266):529.

3. Al Seadi T. Biogas handbook. Odense, Denmark: Syddansk Universitet; 2008.

4. Awe OW, Zhao Y, Nzihou A, Minh DP, Lyczko N. A Review of Biogas Utilisation, Purification and Upgrading Technologies. Waste Biomass Valor. 2017 Mar 1;8(2):26783.

5. Ghasemzadeh K, Basile A, lulianelli A. Progress in Modeling of Silica-Based Membranes and Membrane Reactors for Hydrogen Production and Purification. ChemEngineering. 2019;3(1):2.

6. Uhlhorn R, Keizer K, Burggraaf A. Gas transport and separation with ceramic membranes. Part II. Synthesis and separation properties of microporous membranes. Journal of membrane science. 1992;66(2-3):271-87. 
7. Keizer K, Uhlhorn R, Burggraaf A. Gas separation mechanisms in microporous modified Y-Al2O3 membranes. Journal of Membrane Science. 1988;39(3):285-300.

8. Sun $\mathrm{G}$, Hidajat K, Kawi S. Ultra thin Pd membrane on $\alpha$-Al2O3 hollow fiber by electroless plating: high permeance and selectivity. Journal of membrane science. 2006;284(1-2):110-9.

9. Maneerung $\mathrm{T}$, Hidajat $\mathrm{K}$, Kawi S. Triple-layer catalytic hollow fiber membrane reactor for hydrogen production. Journal of Membrane Science. 2016;514:1-14.

10. Maneerung $\mathrm{T}$, Hidajat $\mathrm{K}$, Kawi S. Ultra-thin $(<1 \mu \mathrm{m})$ internally-coated $\mathrm{Pd}-\mathrm{Ag}$ alloy hollow fiber membrane with superior thermal stability and durability for high temperature $\mathrm{H} 2$ separation. Journal of membrane science. 2014;452:127-42. 